\title{
Del blog de LIJ 2.0 al booktuber en la promoción del hábito lector
}

From the blog of LIJ 2.0 to the booktuber on the promotion of the reading habit

\author{
Dr. José Rovira Collado \\ Departamento de Innovación y Formación Didáctica \\ Univesidad de Alicante \\ jrovira.collado@gcloud.ua.es
}

\begin{abstract}
Resumen
Para el correcto desarrollo del hábito lector desde las edades más tempranas, debemos superar el enfrentamiento entre lectura tradicional y digital. En este sentido, las nuevas herramientas de la web social nos ofrecen dinámicas de participación e interacción con la lectura, apareciendo el concepto de LIJ 2.0 (Literatura y Lectura Infantil y Juvenil en la Web Social) y de Lectura Social. En el siguiente trabajo se comparan dos dinámicas de participación propias de esta nueva forma de promover el hábito lector: los blogs y las reseñas audiovisuales o booktubers. En primer lugar, los blogs "lijeros" son el primer espacio de desarrollo de la LIJ 2.0 con centenares de propuestas y muy variadas modalidades para difundir, comentar o estudiar la literatura infantil y juvenil. En segundo lugar, los booktuber han obtenido en los últimos años una gran atención por el público juvenil y ofrecen una nueva manera de promocionar la lectura.
\end{abstract}

\begin{abstract}
For the correct development of reading habits from an early age, we must overcome the confrontation between traditional and digital reading. In this sense, the new tools of the social web offer us dynamics of participation and interaction with reading, the concepts of LIJ 2.0 (Children's and Youth's Literature and Reading in the Social Web) and Social Reading appearing. In this paper we compare two dynamics of this new way to promote the reading habit: the blogs and the booktubers. First, the blogs "lijeros" are the first space development of LIJ 2.0 with hundreds of proposals and varied ways to disseminate, discuss or study children's literature. Second, the booktubers have gained in recent years considerable attention by the youth audience and offer a new way to promote reading.
\end{abstract}

Palabras clave: Lectura Social, Blogs, LIJ, Booktubers

Keywords: Social Reading, Blogs, LIJ-Children's and Youth's Literature, Booktubers

\section{Introducción. Hablando y escribiendo sobre literatura en la web social}

La rápida evolución e implantación de las herramientas digitales de interacción social (móviles, tabletas, libros electrónicos, wearables y otros dispositivos móviles) y la ampliación del acceso de banda a Internet (cobertura 4G y fibra óptica), llevan ligada la consolidación de programas y aplicaciones (mensajería móvil, microblogs y redes sociales), elementos propios de lo que denominamos Web 2.0, que favorecen y transforman las posibilidades de comunicación humana a través de Internet. 
Si consultamos algunas de las páginas que reflejan la velocidad de incorporación de nuevos contenidos a la red, como por ejemplo The Internet in Real-Time, ${ }^{2}$ descubriremos como, junto con las redes sociales (Facebook y Twitter) y la mensajería móvil (Whatsapp), los grandes repositorios audiovisuales (Youtube) son los que tienen mayor velocidad de incorporación de contenidos.

Muchos de estos avances están transformando nuestra interacción y participación con la red, volviéndola mucho más audiovisual que hace menos de diez años. Aunque esto pudiera parecer un problema para el desarrollo de la competencia lectoliteraria y el desarrollo del hábito lector, estas transformaciones llevan asociadas nuevas formas de lectoescritura multimedia y nuevos productos artísticos como las Narrativas Transmedia o la Literatura Electrónica.

Junto a estos cambios aparecen nuevas dinámicas en el acceso a la lectura y la difusión de esta, como los blogs y otras publicaciones periódicas digitales, los repositorios de obras y las bibliotecas digitales y los espacios de intercambio de archivos, o nuevos espacios de discusión como los foros o las redes sociales de lectura (Lluch, 2011 y Rovira, 2015). También podemos hablar de transformaciones en la escritura como los espacios colaborativos (wikis o documentos en la nube tipo Google Drive) o posibilidades de autopublicación a través de distintas plataformas, como Amazon, por mencionar la más conocida. Como muchos expertos afirman, en contra de la opinión generalizada, se lee y se escribe más que nunca. La integración de propuestas de creación audiovisual en nuestra práctica docente son cada vez más amplias (Giráldez, 2015) y no debemos considerarlas un enemigo del desarrollo del hábito lector.

En este sentido compararemos dos propuestas digitales para la formación del lector literario. Para comenzar, reivindicaremos la importancia de los blogs como espacio central de esta nueva manera de crear, difundir, comentar, promocionar y estudiar cualquier tipo de literatura. A continuación, presentaremos los booktubers como un nuevo espacio de promoción lectora. Estas reseñas literarias en formato vídeo nos ofrecen las impresiones de lectores y lectoras juveniles principalmente. Estamos dentro de una nueva evolución digital de los medios audiovisuales y debemos aprovecharla en nuestras propuestas didácticas: "composing using a medium like YouTube can help involve students in their own learning process" (Sorensen y Mara 2014, p. 95).

\section{Marco Teórico. Hábitos de lectura (social) en los nuevos espacios digitales}

En los últimos años hemos tenido la fortuna de conocer diversos estudios sobre los hábitos de lectura en España, realizados por distintas instituciones. El primer ejemplo, que podemos considerar un hito en la publicación de este tipo de análisis, es el informe Hábitos de lectura y compra de libros en España 2012 (Conecta 2013). En él encontramos una completa radiografía sobre la lectura en nuestro país entre 2010 y 2012 y las rápidas transformaciones que se avecinaban. De toda la rica información, destacamos la información recogida sobre la lectura digital (Conecta 2013, pp. 68-77).

\footnotetext{
${ }^{2}$ En la página https://goo.gl/Wizwlb_ encontramos los principales espacios de Internet y cómo va creciendo la información que recogen cada segundo. En una nota final indica "By the way, in the 62 seconds you've been on this page, approximately 1399588 GB of data was transferred over the internet."
} 


\section{ÍNDICE DE LECTORES EN SOPORTE DIGITAL EN ESPAÑA} QUÉ LEEN EN SOPORTE DIGITAL

\section{\% LECTORES EN SOPORTE DIGITAL}

Base: Población de 14 ó más años (6380)

\begin{tabular}{|c|c|c|c|c|c|c|}
\hline & & & & & \multicolumn{2}{|c|}{ Respuesta múltiple } \\
\hline \%Horizontales & $\begin{array}{c}\text { Total } \\
\text { Lectores } \\
\text { En soporte } \\
\text { Digital }\end{array}$ & $\begin{array}{c}\text { Web, } \\
\text { Blogs, } \\
\text { Foros, ... }\end{array}$ & Prensa & Libros & Revistas & Comic \\
\hline & $\%$ & $\%$ & $\%$ & $\%$ & $\%$ & $\%$ \\
\hline TOTAL & 58,0 & 46,9 & 38,0 & 11,7 & 7,3 & 3,9 \\
\hline \multicolumn{7}{|l|}{ SEXO } \\
\hline Hombre & 65,6 & 53,5 & 47,7 & 12,9 & 9,3 & 5,9 \\
\hline Mujer & 50,4 & 40,3 & 28,4 & 10,4 & 5,4 & 1,8 \\
\hline \multicolumn{7}{|l|}{ EDAD } \\
\hline De 14 a 24años & 88,6 & 77,9 & 45,8 & 20,3 & 11,8 & 10,0 \\
\hline De 2534 años & 83,0 & 71,4 & 56,0 & 20,1 & 10,8 & 7,6 \\
\hline $\begin{array}{r}\text { De } 35 \text { a } 45 \\
\text { años }\end{array}$ & 65,3 & 52,2 & 45,7 & 10,6 & 9,3 & 1,8 \\
\hline $\begin{array}{r}\text { De } 35 \text { a } 45 \\
\text { años }\end{array}$ & 52,4 & 40,9 & 37,0 & 7,8 & 5,7 & 2,1 \\
\hline $\begin{array}{r}\text { De } 45 \text { a } 54 \\
\text { años }\end{array}$ & 39,3 & 27,9 & 28,9 & 9,2 & 5,3 & 2,0 \\
\hline $\begin{array}{r}\text { De } 55 \text { a } 64 \\
\text { años }\end{array}$ & 18,9 & 10,6 & 12,4 & 2,5 & 0,9 & 0,3 \\
\hline $\begin{array}{r}\text { De } 55 \text { a } 64 \\
\text { años }\end{array}$ & 39,3 & 27,9 & 28,9 & 9,2 & 5,3 & 2,0 \\
\hline 65 años y más & 18,9 & 10,6 & 12,4 & 2,5 & 0,9 & 0,3 \\
\hline
\end{tabular}

Figura 1. Hábitos de lectura y compra de libros en España 2012 (Conecta 2013, p. 70)

En la anterior gráfica queremos destacar el número total de lectores en soporte digital, siendo más de $50 \%$ en el total de la encuesta y superando el $80 \%$ en la franja entre 14 y 34 años. Además, la tipología de textos a los que se accede es, mayoritariamente, Webs, Blogs y Foros, con más de $70 \%$ en la citada franja. A partir de los datos de esta encuesta, encontramos distintas investigaciones que analizan los cambios producidos en los últimos años en la lectura (Fernández-Blanco, Prieto-Rodríguez y Suarez-Pandiello, 2015). La consolidación en el mercado de nuevos dispositivos de lectura digital (ebooks y tabletas) permite el enorme crecimiento de lectores digitales. Según Arévalo, Cordón y Gómez (2014, p. 12):

De cualquier modo los datos que arrojan los barómetros de los últimos años muestran modificaciones interesantes en las prácticas de lectura y compra de libros. En el año 2005 un $3,2 \%$ de los usuarios utilizaban la red para la compra de libros, con un promedio de libros comprados de 3,7. Pero un 35\% utilizaba la red para buscar información sobre libros, y un $20 \%$ leía la prensa en internet. Los datos relativos al año 2006 son bastante similares. Sin embargo en el año 2007 se comienzan a producir cambios significativos. El porcentaje de usuarios que compran libros en la red se triplica, llegando al $11,1 \%$, la consulta de prensa y revistas digitales alcanza porcentajes en torno al $57 \%$, y la lectura y descarga de literatura en la red se sitúa en el 
17\%. Hay que tener en cuenta que 2007 es el año de despegue de los dispositivos de lectura electrónicos de nueva generación con pantallas de tinta digital, con Kindle y Sony como abanderados del nuevo sistema, y que la oferta de libros electrónicos empieza a emerger con pujanza en los sitios de Amazon y otras plataformas digitales.

Aunque parece que los últimos datos indican un estancamiento de esta evolución de la lectura hacia lo digital, la mayoría de estas investigaciones confirman las transformaciones que se han producido en los últimos quince años siendo la lectura digital una realidad. Según el informe El Sector del Libro en España, 2013-2015 (Observatorio del Libro, 2015, p. 16):

La edición de libros digitales muestra respecto al año anterior un descenso del 1,9\%, con un total de 20.263 ISBN. Su peso sobre el total de la oferta retrocede del 23,2\% al 22,3\%. Con estos datos se invierte por primera vez la tendencia iniciada en 2008 hacia el aumento de la edición digital en detrimento de la edición impresa.

Otras investigaciones como la de Conecta (2014) sobre la lectura en dispositivos móviles muestra como esta se multiplicó entre diciembre de 2010 y enero de 2014, alcanzando casi a un $30 \%$ de la población.

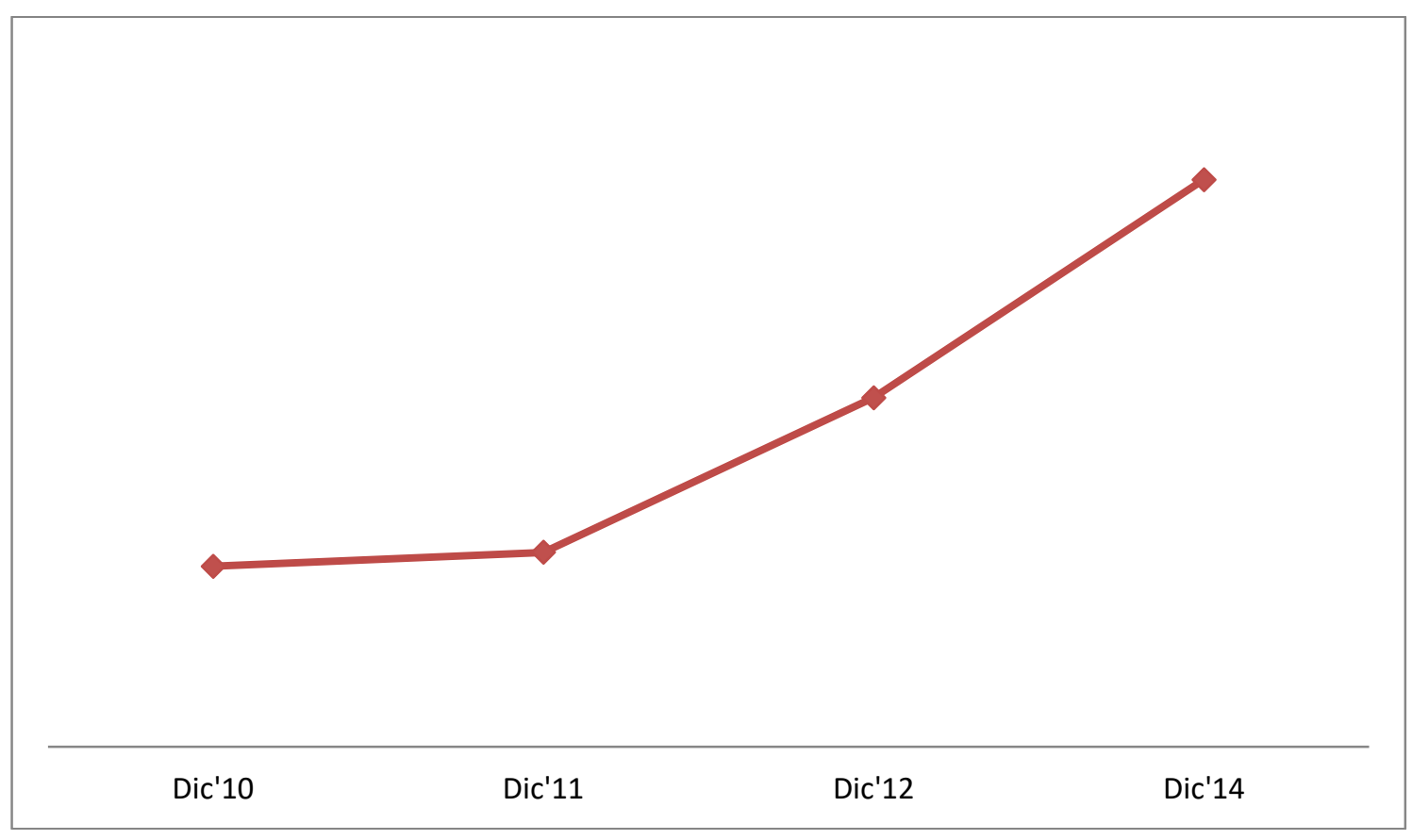

Figura 2. La lectura en dispositivos móviles 2014 (Conecta 2014, p. 6)

Esta investigación informa también sobre la tipología de lecturas en soportes digitales (libros, prensa, blogs, cómics...) y los lugares donde se lee (casa, trabajo, transporte público...). La generalización de dispositivos móviles y el abaratamiento de sus servicios, junto con la aparición de nuevas plataformas y sistemas de distribución, nos sitúa ante un presente donde la lectura digital, sobre todo en las franjas de edad más jóvenes, es una práctica habitual y contrastada. 
a) Lectura Social y LIJ 2.0

Después de confirmar la creciente presencia de la lectura digital en los distintos soportes, es necesario definir las nuevas dinámicas de interacción lectora como son los conceptos de Lectura Social y LIJ 2.0. Estas nuevas formas de participación permiten a cualquier lector compartir sus lecturas de muy diversas maneras.

La lectura social o lectura 2.0 definen una nueva realidad donde las labores de mediación lectora se transforman, o incluso se ven sustituidas por las posibilidades de conexión que ofrece Internet permitiendo la interacción entre lecturas y lectores. Lluch y Barrena (2007) plantean la importancia de los foros de Internet sobre obras literarias, donde los jóvenes lectores pueden participar y compartir su opinión sobre las distintas lecturas. La labor editorial se transforma a través de espacios para mantener contacto directo con los lectores: "Esta nueva manera de comunicarse con el lector directamente libera al libro o al editor del lastre del mediador, de pensar qué le podía gustar dado que era el que recomendaba el libro al lector, y le permite proponer un relato adecuado a los gustos del lector" (Lluch y Barrena 2007, p. 9). Aunque esta lectura 2.0 se produce en cualquier ámbito y edad, es durante la etapa juvenil cuando se van adoptando estas dinámicas. En los últimos años han aparecido distintas investigaciones en torno a este concepto, donde se describen dinámicas de la lectura social y se demuestra la importancia de la participación en distintos medios sociales para la promoción de la lectura (Lluch, 2014a). Algunas de las características de esta lectura 2.0 son:

1. Los sujetos crean comunidades virtuales de lectura. Posiblemente, la principal conclusión de la investigación tiene que ver con las nuevas formas de crear comunidades de lectores que ya no se generan ni se tutelan desde la escuela o la biblioteca.

2. Los lectores crean los espacios, ganando protagonismo y visibilidad. Aunque la editorial o la autora colaboran o intervienen, el usuario es el que produce los contenidos adaptándolos a las normas y a las características de cada red social y de cada plataforma; como consecuencia, el efecto viral de los mensajes es mucho mayor.

3. El hecho lector se transforma en conversación social. Los espacios analizados son menos forzados y más cercanos que la escuela o la familia porque, como comentan en diferentes documentos, conectan con otros que tienen aficiones similares y que pueden convertirse en amigos. En este nuevo contexto, la lectura deja de ser una afición que provoca aislamiento para transformarse en un constructo de conversaciones (Lluch 2014a, pp. 17-18).

Cordón García y Gómez Díaz también describen la lectura social y colaborativa, en una entrada específica del DINLE (2013):

La lectura social o colaborativa es aquella que se desarrolla en plataformas virtuales configurando una comunidad que desarrolla formas de intercambio diversas, compartiendo comentarios, anotaciones, valoraciones, etiquetas y, en algunos casos, libros y lecturas. (...) 
Las plataformas de lectura social han experimentado un crecimiento importante en los dos últimos años, al hilo de la evolución de la lectura digital y de las posibilidades tecnológicas ofrecidas por los dispositivos de lectura. (...)

Como hemos visto en las anteriores gráficas, el mayor porcentaje de lectura digital se da entre los 14-24 años. Por tanto, es lógico suponer que el tipo de lecturas que realicen este tipo de lectores estarán relacionadas, en gran parte, con la literatura infantil y juvenil (LIJ), ya que su formación lectora y digital se ha ido desarrollando anteriormente. En este sentido se ha desarrollado el concepto de LIJ 2.0, siglas que responden al concepto Literatura y Lectura Infantil y Juvenil en la web social (Rovira 2011 y 2015). En él se engloban las distintas formas de representación de la LIJ en los espacios propios de la web social: Blogs y Wikis en primer lugar y redes sociales como Facebook Twitter como nuevos espacios de desarrollo. El concepto incluye también la idea de lectura junto con la sigla tradicional de LIJ ya que hay distintos elementos de la LIJ 2.0 que no son propiamente literarios. Los blogs de LIJ o "lijeros" tal como los define Gómez Soto (2011) son la base de esta transformación de la LIJ en Internet. Ibarra y Rovira (2012) hacen un repaso sobre los distintos espacios que engloba el término, así como de las nuevas posibilidades que han ido apareciendo en los últimos años, como los booktubers. Otro de los informes institucionales sobre el libro infantil y juvenil (Observatorio Lector, 2014) recoge la aparición de dicho término para describir las nuevas interacciones en la red:

\footnotetext{
La revolución digital hace posible que surja la LIJ 2.0 que ofrece entre otras cosas la posibilidad de comunicación directa e inmediata entre los lectores y de los lectores con el autor (Observatorio de lectura y el libro, 2014, p. 46).

Esta interacción nos lleva al concepto de LIJ 2.0, (...), que entre otros rasgos se caracteriza por una comunicación directa entre los lectores que genera un intercambio de opiniones y experiencias en tiempo real y por encima de las fronteras físicas. Porque además de leer, el lector quiere hablar y recomendar lo que lee y para ello Internet es el medio ideal ya que permite hacerlo de manera masiva y amplificada (Observatorio de lectura y el libro, 2014, p. 26).
}

\section{Análisis y comparación de dos espacios de la LIJ 2.0}

Una vez analizados los conceptos de LIJ 2.0 y lectura social procedemos a presentar dos espacios que forman parte de la evolución. Los blogs como elemento central y pilar de su desarrollo y los booktubers como una evolución del modelo de reseña y comentario general de LIJ en Internet hacia los nuevos formatos audiovisuales.

\section{a) Blogs de LIJ 2.0}

Desde que se acuñó el concepto de LIJ 2.0 en 2008 para describir las particularidades propias de los blogs de literatura infantil y juvenil, quedó claro que estos eran el espacio central de dicha transformación. Aunque las redes sociales han ampliado las posibilidades de interacción y han aparecido otras muchas formas como la que veremos a continuación, la lectoescritura de blogs de LIJ sigue siendo el eje central de todas estas dinámicas sociales, más allá de la lectura del propio texto literario. En algún momento de este proceso digital de mediación y promoción lectora siempre nos encontraremos con un blog, con múltiples posibilidades y recomendaciones de lectura. En este sentido, la entrada, como elemento epitextual respecto a una obra de LIJ, es la unidad de 
organización de estos blogs, aunque encontramos otros elementos como los comentarios o las etiquetas.

En la web encontramos incontables propuestas de muy distinto tipo. En un primer análisis estos blogs pueden parecer similares a cualquier otro blog literario, pero las características de creación (escritura e ilustración) y las distintas etapas madurativas de los lectores, nos permiten encontrar espacios muy diferentes:

Existen interacciones entre casi todos los grupos que he planteado: ilustradores que escriben (viceversa, mucho menos), escritores que reseñan, cuentacuentos y maestros que escriben, librerías que editan o que tienen clubes de lectura... lo que hace que cada blog sea una excepción en sí mismo, un híbrido inclasificable. Hay tantos tipos de blogs como gente que los hace, las aproximaciones a la LIJ son múltiples y eso es bueno. (Gómez Soto, 2011, p. 30).

Rovira Collado (2015, pp. 639-661) recoge una selección de listados de blogs de LIJ con un corpus de más de doscientos ejemplos analizados. De los listados, podemos destacar los siguientes:

- Jorge Gómez Soto. Blogroll en Literatura Infantil y Juvenil Actual [https://goo.gl/NEJexZ / Además incluye una página de escritores y otra de ilustradores con más de doscientos enlaces.

- Mario Aller, Educacontic (2010) "Literatura infantil en la red"[ https://goo.gl/xEVbl5]

- Educació i les TIC (2014) "60 blogs de literatura infantil y juvenil" [https://goo.gl/mXmn5e / ]

- Literatura SM 2014 "Profes que hablan de lengua y literatura en la red”[https://goo.gl/e7Odji]

- Educación Tres Punto Cero. (2014) "Blogs dedicados a la Literatura Infantil" [https://goo.gl/GPY7kQ]

- José Rovira-Collado (2009) Estudiando la LIJ en la web social "Cuéntanos tu blog" [https://goo.gl/GRpCUi]

A partir de estos listados podemos introducirnos en una amplia blogosfera "lijera". Desde una perspectiva académica, García y Rubio (2013) hacen un completo análisis de ésta con más de ochenta ejemplos y proponen una clasificación muy detallada basada en los criterios de "Autoridad" y "Contenido" con múltiples posibilidades en cada rama:

\begin{tabular}{|c|c|c|c|c|}
\hline \multicolumn{5}{|c|}{ ATENDIENDO A SU AUTORIDAD } \\
\hline Personales & Corporativos & $\begin{array}{c}\text { Organismos, } \\
\text { instituciones }\end{array}$ & $\begin{array}{c}\text { Bibliotecas } \\
\text { infantiles y } \\
\text { escolares }\end{array}$ & $\begin{array}{c}\text { Revistas } \\
\text { especializadas }\end{array}$ \\
\hline $\begin{array}{c}\text { Escritores } \\
\text { Ilustradores } \\
\text { Lectores } \\
\text { Niños }\end{array}$ & $\begin{array}{c}\text { Editoriales } \\
\text { Llj en general } \\
\text { Colecciones. } \\
\text { Sagas ... } \\
\text { Adultos }\end{array}$ & Librerías & $\begin{array}{c}\text { Noticias, } \\
\text { actividades, } \\
\text { Recomendaciones, } \\
\text { Club de lectura }\end{array}$ & \\
\hline
\end{tabular}




\begin{tabular}{|c|c|c|}
\hline \multicolumn{3}{|c|}{ ATENDIENDO A SU CONTENIDO } \\
\hline Críticas, reseñas y noticias & $\begin{array}{c}\text { Académicos y de } \\
\text { investigación }\end{array}$ & Blog de blogs \\
\hline $\begin{array}{c}\text { L1J en general } \\
\text { Libros electrónicos }\end{array}$ & $\begin{array}{c}\text { LlJ } \\
\text { Específicos para un género o edad }\end{array}$ & Promoción de lectura \\
\hline
\end{tabular}

Figura 3. Clasificación de blogs "lijeros" (García y Rubio 2013, p. 55).

A partir de esta clasificación García, Gómez, Cordón y Arévalo (2014) han hecho una investigación de las características de estos blogs a través del uso que realizan de las etiquetas, elementos centrales para conocer el contenido semántico de estos blogs.

A la hora de analizar estos blogs, en primer lugar debemos destacar sus enormes posibilidades de aprendizaje. Los blogs se convierten en una vía de entrada a la web social ya que permiten desde las primeras edades la participación del lector a través de comentarios y posteriormente con la creación de nuevos espacios. El interés por el fomento de la lectura y el desarrollo del hábito lector lo podemos encontrar en otras recopilaciones de blogs, como sucede por ejemplo con el listado de Ramos Molina (2016) centrado en sus posibilidades didácticas. Aunar el interés que despierta la LIJ con las posibilidades digitales es una de las opciones que nos ofrecen este tipo de blogs:

Partiendo de la indiscutible utilidad didáctica, los blogs de LIJ tienen unas características específicas. (...) En esta práctica docente se integran el desarrollo de la competencia lectoliteraria con la alfabetización digital. El conjunto de ambas competencias podrían ser aplicables al desarrollo de la alfabetización mediática, donde la participación y la producción elaborada de escritos por parte de los estudiantes, también se realizaría a través de entradas en los blogs. Creemos que para el desarrollo común de la competencia literaria y la competencia digital, los blogs suponen el espacio principal, ya confirmado por múltiples experiencias desde el ámbito de la didáctica de la lengua y la literatura. (Rovira y Llorens 2012, p. 810).

Desde una perspectiva teórica y siguiendo a Genette, podemos definir estos elementos paratextuales como epitextos porque están fuera de la obra literaria pero nos ofrecen mucha información sobre ella y nos ayudan en la promoción de su lectura. Aunque la mayor parte del consumo de estos productos se realiza fuera del aula y de las lecturas obligatorias, es necesario que se conviertan en práctica habitual del profesorado. Lluch afirma que:

\footnotetext{
Muchas de las actividades que hacen en internet, como compartir, leer, redactar, organizar, buscar, valorar, clasificar o utilizar archivos multimedia, podemos utilizarlas para leer y escribir sobre las lecturas, para compartirla con conocidos o desconocidos, para aprender, para crear una comunidad unida por la lectura $(2011$, p. 91).
}

b) Booktubers. Una propuesta propia de la LIJ 2.0.

Es un movimiento bastante reciente pero no se ha identificado quién fue la primera persona en subir a Youtube un vídeo haciendo una reseña literaria, y se ha consolidado en muy pocos años con un gran éxito, sobre todo en los lectores juveniles. Pates (2015) sitúa su aparición en Estados Unidos en 2009 aunque es entre 2012 y 2013 cuando aparecen ejemplos en español (Pacheco-Alonso, 2014). Por su sencillez, podemos 
considerarlos como el primer espacio de la $L I J$ 2.0 audiovisual, donde se recoge miles de experiencias con millones de reproducciones. Estas reseñas orales, generalizadas bajo el término booktuber, son una evolución hacia el vídeo y la expresión oral de lo que en los blogs hemos denominado lectura social. Carbajo (2014) define así esta tendencia:

\begin{abstract}
Jóvenes, mayormente chicas adolescentes, se ponen delante de una cámara y hablan de los libros que leen. No es el típico haul vlogger que nos comenta inocentemente (o no) sus últimos delirios consumistas relacionados con la moda, la belleza o cualquier cachivache electrónico. Aunque el sistema y la forma de manifestarse ante la audiencia es el mismo, el objeto es diferente: hablamos de libros juveniles y de todo lo que rodea a los mismos. Es YouTube, una vez más, la plataforma elegida para que jóvenes aficionados a la lectura, heridos por la letra, den rienda suelta a su pasión, a su fetichismo libresco, al placer incipiente del coleccionista de libros (Book $\mathrm{Haul}$ ). Les gusta mostrar sus maravillosos libros baratos conseguidos en librerías de segunda mano. Nos hablan de los chollos que hay en Internet si queremos comprar buenos libros de aventuras, ciencia ficción o novela romántica.
\end{abstract}

Los lectores y las lectoras juveniles son quienes principalmente comparten la opinión de sus lecturas, siendo una herramienta de promoción editorial importantísima porque además se comunican con otras personas de su edad usando su propio lenguaje, donde es evidente el dominio de la comunicación audiovisual y la técnica. Esta moda traslada el fenómeno youtuber al fomento de la lectura y confirma que los jóvenes actuales leen más que nunca. Estas herramientas 2.0 son también corriente de transmisión y muestra palpable de la lectura infantil y juvenil. Han sido los espacios de mayor desarrollo de la LIJ 2.0 en los últimos tres años, como puede apreciare en la comunidad de Facebook con más de ocho mil integrantes: https://goo.gl/CZ6xKj. Esta nueva modalidad amplia el sentimiento de comunidad antes citado.

El vídeo Booktube, el documental (2013) — trabajo escolar con más de 200.000 reproducciones - nos ofrece un rápido panorama del fenómeno y el éxito que está teniendo, principalmente en Latinoamérica, a través de varios protagonistas que cuentan con miles de seguidores. Alberto Villarreal (2013), cuyo perfil es Abriendo Libros, un booktuber con más de trece mil suscriptores comenta: "Yo creo que las personas están interesadas en nuestros vídeos porque es algo muy personal. Una persona con una cámara, se siente muy personal, a diferencia de los blogs porque aquí es una persona que da la cara y se siente más como una amistad".

A continuación, ofrecemos cinco canales de booktubers con distintas características, cuyas cifras de seguidores y reproducciones se han triplicado en menos de un ñao, evidenciando con ello el interés que despiertan en este momento:

- Fátima Orozco [https://goo.gl/UaN2Tp] Creado en julio de 2012 su canal tiene más de trescientos mil suscriptores y cada vídeo supera rápidamente las cincuenta mil reproducciones y ha superado los 17 millones de visitas. Es posiblemente el principal ejemplo en Hispanoamérica (Sánchez 2015) y se ha convertido en un referente cultural para los adolescentes aficionados a la lectura.

- Sebastián G. Mouret, El Coleccionista de mundos [https://goo.gl/GFPON8] con casi ciento sesenta mil suscriptores y más de seis millones reproducciones, su 
éxito le ha permitido colaborar con la revista digital de literatura juvenil $E l$ tempo de las mil puertas [https://goo.gl/Mh9rwl].

- Javier Ruescas, [https://goo.gl/D2YDKJ] es el principal ejemplo de autor y editor que usa todas las herramientas 2.0 para la promoción de sus obras. Su canal tiene más de ciento once mil suscriptores y cinco millones de reproducciones y además de críticas de libros incluye consejos editoriales, talleres de escritura y entrevistas.

- Gemma Lienas [https://goo.gl/On8nfA] Este es un ejemplo de que la LIJ2.0 no es exclusiva de los jóvenes ya que es una autora con más de cincuenta libros.

- Marta Botet https://goo.gl/67GtCG es una joven lectora que comenzó su blog con once años https://goo.gl/chKf31 y que luego empezó con reseñas audiovisuales que demuestran que también hay espacio para obras más infantiles y lectoras más jóvenes.

- [En Internet encontramos otros listados como por ejemplo "Los diez mejores booktubers en español." https://goo.g1/92nE2r].

En 2014, Ana Garralón, especialista en LIJ, desató una desafortunada polémica por plantear algunas críticas al modelo, sobre todo por la repetición de las obras que se reseñan, muchas superventas juveniles, o por la falta de profundidad de algunos análisis, obvia también por la etapa formativa tanto de los protagonistas de los vídeos como de su audiencia. En nuestra opinión consideramos los booktubers como una dinámica muy relevante para el desarrollo del hábito lector, dado que muchas veces están haciendo un trabajo entre iguales. Es una actividad lúdica en torno a lectura literaria que surge fuera de las aulas y sus principales protagonistas ya se han convertido en estrellas de Internet y no se plantean un fin didáctico. A raíz de esta polémica, también hemos podido comprobar el sentimiento de comunidad que se crea en torno a esta experiencia, ya que hubo una rápida respuesta a las críticas a través de las redes sociales tanto de booktubers como de sus seguidores. Sorensen y Mara (2014) la definen como una "Comunidad conectada de conocimiento" en torno a la lectura. Pero además plantean la utilidad de incorporar esta dinámica en nuestra práctica escolar, ya que permite incrementar el aprendizaje de nuestro alumnado:

Teachers who incorporate the creation of "BookTubers" or other identity-bound grassroots genres into their curriculum could facilitate the interactive, borderless, social, and collaborative possibilities of such an $\mathrm{NKC}$ in the classroom environment, thereby increasing learning and engagement through student production of videos and other multimodal texts (Sorensen y Mara, 2014, p. 88)

Lluch (2014b [entrada: "De booktubers o exposiciones orales para presentar una lectura. ¿Cómo lo hacemos?”]) destaca las posibilidades didácticas de este formato y cómo lo podemos aprovechar para mejorar la expresión oral en las aulas. En España encontramos un precedente a esta práctica en el blog Kuentalibros[https://goo.gl/DMM8bp] uno de los proyectos colaborativos más destacados durante los últimos años, pero en este caso con un claro objetivo didáctico (Ambrós, 2015). Un equipo de docentes empezó a grabar reseñas de libros para sus clases. Posteriormente el proyecto se abrió a otros centros y cualquier persona podía enviar su vídeo con información para la entrada. Nació en 2011 y fue clausurado en 
junio de 2013 con casi dos mil entradas y más de un millón de visitas ${ }^{3}$. En las grabaciones encontramos reseñas orales tanto de alumnado de Educación Primaria, Secundaria, Bachillerato y estudios superiores, como de docentes de todas esas etapas.

Como ya hemos mencionado, estas nuevas dinámicas digitales, apoyadas por las posibilidades de las redes sociales, configuran un sentido de comunidad muy marcado. Al igual que otros Youtubers, los protagonistas se convierten en líderes de audiencia que influyen sobre los gustos literarios de una comunidad. Es cierto que la mayoría de las obras son las más promocionadas, muchas dentro de la categoría conocida como Young Adult ${ }^{4}$. Ravettino (2015, pp. 6-9) hace un recorrido sobre las obras más reseñadas y también sobre sus características principales de estas, que pueden influir en la configuración de los gustos de una generación de jóvenes lectores.

Además, las prácticas que se representan en los distintos vídeos generan un nuevo lenguaje, con gran influencia del inglés. En la nota en la web de la editorial SM dedicada a los booktubers encontramos el siguiente listado con los nuevos términos utilizados por esta comunidad.

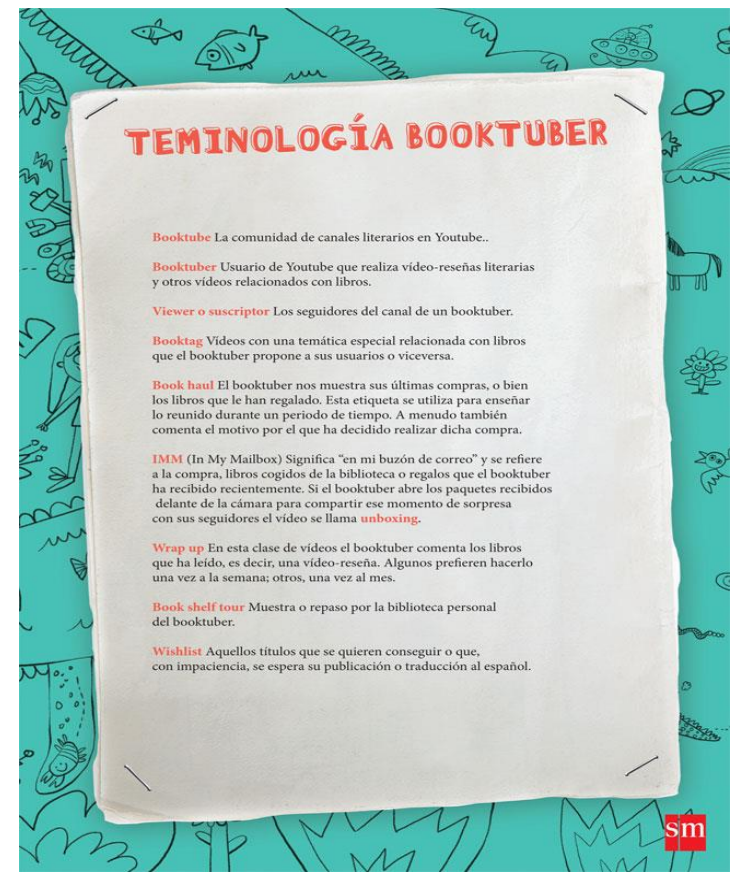

Figura 4. Terminología Booktuber. Editorial SM, 3 de Marzo 2016 [https://goo.gl/2rngQe].

Pates (2015, p. 127) comenta la relevancia de estos términos para identificar las nuevas dinámicas de actuación en los vídeos: compras, listas de lectura, concursos... La Revista Babar también le dedica una completa noticia al nuevo vocabulario relacionado con

\footnotetext{
${ }^{3}$ Con esta experiencia como referente, podemos encontrar nueva propuestas que llevan el Booktuber al aula, como por ejemplo el alumnado de Lengua y Literatura para la Educación Primaria de la Universidad de Alicante que realiza distintas reseñas para sobre obras de Literatura Española https://goo.gl/NTK8Oi

${ }^{4}$ La categoría Young Adult se refiere a obras juveniles, de gran éxito y que muchas veces se configuran como sagas, que también tienen aceptación entre el público adulto. En la red social de lectura Goodreads hay un foro abierto sobre el tema que se centra en este aspecto, titulado "¿Algún booktuber que no reseñe YA?" disponible en https://goo.gl/UTIkl4.
} 
estas nuevas prácticas lectoras en su "Breve diccionario de nuevos términos para lectores despistados" (Soto Helguera, 2015).

\section{Nuevas perspectivas en la LIJ 2.0}

Como hemos visto, los booktubers son una nueva manera de promoción de la lectura y del desarrollo del hábito lector. A continuación, ofrecemos un cuadro comparativo de ambos modelos:

\begin{tabular}{|c|c|}
\hline Blogs & Booktubers \\
\hline Plataformas y programas de edición & Plataformas y repositorios \\
\hline $\begin{array}{l}\text { Múltiples aunque la mayoría los encontramos en } \\
\text { Blogger, Wordpress y Tumblr }\end{array}$ & $\begin{array}{l}\text { Principalmente Youtube, destaca la poca presencia } \\
\text { en Vimeo. Probablemente se incorporarán nuevas } \\
\text { aplicaciones como Periscope o incluso instragram, } \\
\text { apareciendo el concepto bookstagrammers }\end{array}$ \\
\hline Tipología de blogs & Tipología de booktubers \\
\hline $\begin{array}{l}\text { Múltiples según la clasificación de García y Rubio } \\
\text { 2013, se dividen según autoría y contenido. }\end{array}$ & $\begin{array}{l}\text { Dentro de la categoría general de Youtuber cada } \\
\text { vez aparecen más tipos distintos de vídeos. En los } \\
\text { booktuber, aunque hay algunas variantes la } \\
\text { mayoría son reseñas juveniles. }\end{array}$ \\
\hline Autoría & Autoría \\
\hline $\begin{array}{l}\text { Autores/as; Lectores/as; } \\
\text { editores/as, bibliotecarios/as; docentes familiares. }\end{array}$ & $\begin{array}{l}\text { Aficionados/as de LIJ, en algún caso autores/as de } \\
\text { este tipo de obras. }\end{array}$ \\
\hline Edad de autoría y la audiencia & Edad de autoría y la audiencia \\
\hline $\begin{array}{l}\text { Cualquiera, desde jóvenes lectores que buscan en } \\
\text { los blogs nuevas lecturas a docentes y familiares de } \\
\text { cualquier edad. }\end{array}$ & $\begin{array}{l}\text { Principalmente personas jóvenes. Desde los } 12 \text { a } \\
\text { los } 30 \text { años, aunque algunos booktubers han } \\
\text { superado esa edad }\end{array}$ \\
\hline Tipología de la audiencia & Tipología de la audiencia \\
\hline $\begin{array}{l}\text { Múltiple, al igual que la autoría. Gómez Soto } \\
\text { (2011) }\end{array}$ & $\begin{array}{l}\text { Principalmente jóvenes. Se desarrolla el fenómeno } \\
\text { fan. }\end{array}$ \\
\hline Relevancia para el mundo editorial & Relevancia para el mundo editorial \\
\hline $\begin{array}{l}\text { Mucha. Sistema de envío y recomendación de } \\
\text { novedades habitual. El blog se ha convertido en un } \\
\text { espacio central de la difusión de la obra. }\end{array}$ & $\begin{array}{l}\text { Cada vez reciben más atención y entran en el } \\
\text { sistema de recomendación. Algunos booktubers } \\
\text { consiguen trabajos remunerados relacionados con } \\
\text { el audiovisual y otros se convierten en autores/as }\end{array}$ \\
\hline Tipo de comunicación & Tipo de comunicación \\
\hline Escrita & Oral \\
\hline Uso del multimedia & Uso del multimedia \\
\hline $\begin{array}{l}\text { Imágenes (fotografías e ilustraciones), } \\
\text { presentaciones de diapositivas, vídeos insertados, } \\
\text { múltiples hiperenlaces a otras entradas del blog o a } \\
\text { otros documentos de la red. }\end{array}$ & $\begin{array}{l}\text { Edición de vídeo. Generación de listas de } \\
\text { reproducción y canales específicos. }\end{array}$ \\
\hline Interacción con otros medios digitales & Interacción con otros medios digitales \\
\hline $\begin{array}{l}\text { Mucha. Redes sociales, microblogging y Redes } \\
\text { sociales de lectura. }\end{array}$ & Mucha. Redes sociales Facebook y Twitter. \\
\hline Otros aspectos destacables & Otros aspectos destacables \\
\hline $\begin{array}{l}\text { Los blogs se consideran uno de los pilares de la } \\
\text { Web 2.0. Aunque muchos plantean su fin y los ven } \\
\text { como obsoletos, siguen siendo una herramienta de } \\
\text { mucha utilidad. }\end{array}$ & $\begin{array}{l}\text { Generación de un nuevo lenguaje y dinámicas de } \\
\text { consumo, como hemos visto anteriormente. }\end{array}$ \\
\hline
\end{tabular}

Tabla 1. Comparativa de Blogs y Booktubers. Elaboración propia 
Algunas de las voces más negativas respecto a los booktubers destacan la poca validez de sus críticas y una selección reducida de las lecturas, repitiéndose siempre las obras más conocidas. Pero por ejemplo, una de las reseñas más visitadas (con más de trescientas mil reproducciones) de Fa Orozco [Fátima Orozco] realizada durante su vista a la biblioteca de Vasconcelos se centra en el Conde Lucanor lo que nos demuestra que también hay espacio para la literatura clásica. Esta nueva vía de animación lectora se produce a través de un nuevo medio, el digital audiovisual, donde la audiencia ocupa un lugar principal en las motivaciones de seguir realizando vídeo-reseñas. Por lo tanto, la edad y los gustos de los lectores-espectadores son criterios fundamentales para mantener su atención.

Aunque tienen un éxito indiscutible, es cierto que ya hay voces que anuncian un cansancio del modelo youtuber. Repetición de contenidos, pérdidas de interés, polémicas innecesarias o el crecimiento de los principales protagonistas (y su audiencia), hacen que ya nos encontramos en un momento de incertidumbre o transición.

Es posible que estas dudas también lleguen al ámbito de los booktubers. No hemos acabado de descubrir una nueva vía de promocionar la lectura y ya habrá voces que la darán por acabada. Este es uno de los peligros de Internet. Como si se debiera a una obsolescencia programada, las modas, o generaciones, se van sucediendo más rápidamente de lo que era habitual. Pero vemos que es un tema de gran actualidad con interés para el mercado editorial, como es el caso de May R. Ayamonte y Esmeralda Verdú que acaban de publicar Besos entre líneas (2016) y que en menos de dos semanas contó con más de veinte reseñas audiovisuales — puede verse https://goo.gl/Og9kKE—, una novela juvenil, cuya temática se centra en los booktubers.

Pero estos mismos miedos llevan planteándose sobre los blogs desde hace varios años. Sin embargo, si repasamos muchos de los perfiles citados comprobaremos que la mayoría aprovecha ambas herramientas para hablar de sus lecturas favoritas. Ambos son espacios de difusión del hábito lector. Como defiende Pates (2015, p. 13): "Es, entonces, que estas experiencias muestran a unos jóvenes que leen una gran cantidad de libros y rompen el imaginario adultocéntrico que sostiene lo contrario".

Los blogs "lijeros" y los booktubers son dinámicas LIJ 2.0 muy importantes para comprender una nueva forma de promover la lectura, difundir la literatura, y favorecer el desarrollo del hábito lector desde las primeras etapas educativas con el apoyo de Internet.

\section{Referencias Bibliográficas}

Alonso-Arévalo, J., Cordón-García, J. A., Gómez-Díaz, R. (2014). Comparación de los Hábitos y Perfil del Lector Digital entre Estados Unidos y España. Anales de Documentación, 17, 1.Recuperado de https://goo.gl/B76ZyF (Consultado el $12 / 5 / 2016)$.

Ambrós, A. (2015). Proyecto Kuentalibros: creación de hipertextos literarios audiovisuales. En O. Cleger y J. M. De Amo (Eds.). La educación literaria y la 
e-literatura desde la minificción. Enfoques hipertextuales para el aula. Barcelona: ICE Universitat de Barcelona.

Asensi Fernández, M. (2015). Booktuber como herramienta para promover la lectura en secundaria. Universidad de Alicante. [TFM-En prensa].

Booktube, el documental (Diciembre de 2013). https://goo.gl/sLgLSZ

Carbajo, S. (2014). BookTubers o la pasión por los libros. En Toyoutome [Blog]. Recuperado de https://goo.gl/6xfHnh (Consultado el 12/5/2016).

Conecta (2013). Hábitos de Lectura y Compra de libros en España 2012. Desarrollado para la Federación de Gremios de Editores, con el Patrocinio del Ministerio de Educación, Cultura y Deporte. Recuperado de: https://goo.gl/PpxE6F(Consultado el 12/5/2016).

- (2014). Informe: La lectura en dispositivos móviles 2014 Recuperado de https://goo.gl/Xw7E3m (Consultado el 12/5/2016).

Cordón García, J. A. et al. (2013). Social Reading: Platforms, Aplications, Clouds and Tags. Oxford: Chandos Publishing.

Cordón García, J. A. y Gómez Díaz R. (2013). Lectura social y colaborativa, Entrada en Diccionario de Nuevas Formas de Lectura y Escritura. Madrid: RIULSantillana.

Fernández-Blanco, V., Prieto-Rodríguez, J., Suarez-Pandiello, J. (2015). [e-Book] A quantitative analysis of reading habits, ACEI working paper series, Recuperado de https://goo.gl/1WCRvX (Consultado el 12/5/2016).

García Rodríguez, A., Gómez Díaz, R., Cordón García, J. A., Alonso Arévalo, J. (2014). Donde viven las etiquetas: el etiquetado en los blogs de literatura infantil y juvenil. En BiD: textos universitaris de biblioteconomia $i$ documentació, diciembre, 33. Recuperado de https://goo.gl/Yjpjim (Consultado el 12/5/2016).

García Rodríguez, A., Rubio González, E. (2013). Un paseo por la blogosfera de la literatura infantil y juvenil española: de los blogs 'lijeros' a Facebook. En: Puntos de Encuentro: Los primeros 20 años de la Facultad de Traducción y Documentación de la Universidad de Salamanca (pp. 51-98). Salamanca: Ediciones Universidad de Salamanca.

Garralón, A. (2014). Retrato del reseñista adolescente. En Revista Letras libres. Recuperado de https://goo.gl/weoDzB (Consultado el 12/5/2016).

Giraldez Hayes, A. (Coord.) (2105). De los ordenadores a los dispositivos móviles. Propuestas de creación musical y audiovisual. Barcelona: Graó.

Gómez Soto, J. (2011). Blogs "lijeros". En N. Ibarra Rius, y J. Rovira Collado (Coords.) (2011). Especial LIJ 2.0 Primeras Noticias de Literatura, 260, 27-34. Barcelona: Comunicación y Pedagogía.

Ibarra Rius, N. y Rovira Collado, J. (2012). LIJ 2.0: De 0 a 100 en (poco más de) diez años. En N. Ibarra Rius, J. Rovira Collado, José (Coords.), (2012). Especial LIJ y Nuevas Tecnologías. Primeras Noticias de Literatura, 269, 41-50. Barcelona: Comunicación y Pedagogía.

Lluch Crespo, G. (2011). Del oral, audiovisual y digital a la lectura (y la escritura) en secundaria. Madrid: Fundación SM. (Núm. 20).

- (2014a). Jóvenes y adolescentes hablan de lectura en la red. Ocnos, 11, 7-20.

- (2014b), "De booktubers o exposiciones orales para presentar una lectura. ¿Cómo lo hacemos?". Disponible en https://goo.gl/0isZ7T (Consultado el 12/5/2016).

Lluch, G. y Barrena, P. (2007). Lectura y literatura infantil y juvenil en la sociedad globalizada. En $15^{a}$ Jornadas de Bibliotecas infantiles, juveniles y Escolares. 
Salamanca: Fundación Germán Sánchez Ruipérez. Salamanca 31 de mayo, 1 y 2 de junio de 2007. Recuperado de https://goo.gl/JbVZrX (Consultado el 12/5/2016).

Observatorio del Libro (2014). Los libros infantiles y juveniles en España 2012-2014 con el Patrocinio del Ministerio de Educación, Cultura y Deporte. Recuperado de: https://goo.gl/DLUh8j (Consultado el 12/5/2016).

Observatorio del Libro (2015). El Sector del Libro en España, 2013-2015 con el Patrocinio del Ministerio de Educación, Cultura y Deporte. Recuperado de https://goo.gl/7DCnU1 (Consultado el 12/5/2016).

Pacheco Alonso, B. (2014). BookTube. Una propuesta para el fomento a la lectura. UNAM. Recuperado de https://goo.gl/CsV7Rz (Consultado el 12/5/2016).

Pates, G. (2015). ¿Los/as jóvenes no leen? Experiencias de lecturas en booktubers. Letras, 1. Centro de Investigación en Lectura y Escritura (CILE) (125-131). Recuperado de https://goo.gl/7bI8FE (Consultado el 12/5/2016).

Ramos Molina, G. (2016). "20 blogs de docentes para educar y crear buenos lectores" en CEDEC-EDUCALABA. Recuperado en https://goo.gl/EGd16c (Consultado el 12/5/2016).

Ravettino Destefanis, A. (2015). Booktubers y performances virtuales: modos contemporáneos de difundir y compartir literatura juvenil en la Red. Ponencia presentada en VIII Jornadas de Jóvenes Investigadores. Eje 4: Producciones, consumos y políticas estético-culturales. Nuevas tecnologías. Buenos Aires, Argentina. Recuperado de https://goo.gl/fyTQqF (Consultado el 12/5/2016).

Rovira Collado, J. (2011). Literatura infantil y juvenil en internet: de la Cervantes Virtual a la LIJ 2.0. Herramientas para su estudio y difusión. En Ocnos, 7, 137151. Recuperado de https://goo.gl/hPbW7v (Consultado el 12/5/2016).

- (2015). Literatura infantil y juvenil en Internet. De la Cervantes Virtual a la LIJ 2.0. Herramientas y espacios para su estudio y difusión [Tesis doctoral] Alicante: Universidad de Alicante. Recuperado de https://goo.gl/3O2f5D (Consultado el 12/5/2016).

Rovira Collado, J. y Llorens García, R. F. (2012). Blogs para la enseñanza de la literatura infantil y juvenil en español. Espacio central de la LIJ 2.0. Perspectiva Florianópolis, vol. 30, 3, 789-816. Recuperado de https://goo.gl/tznGQX (Consultado el 12/5/2016).

Sánchez Sánchez, M. (2015). La joven mexicana que consigue que 200.000 personas se interesen por el Conde Lucanor. En El País. Recuperado de https://goo.gl/afBcHD (Consultado el 12/5/2016).

Soto Helguera, L. A. (2015) "Breve diccionario de nuevos términos para lectores despistados." En Revista Babar 13/04/2015. Disponible en https://goo.gl/kioWQY. (Consultado el 12/5/2016).

Sorensen K. y Mara, A. (2014). Booktubers as a Networked Knowledge Community. En M. Limbu y B. Gurung (2014). Emerging Pedagogies in the Networked Knowledge Society: Practices integrating social media and globalization (pp. 87-99). USA: Information Science Reference. 